\title{
Intracellular electrolyte depletion in patients with ileostomies
}

\author{
L. A. TURNBERG, A. I. MORRIS, P. C. HAWKER, K. J. HERMAN, \\ R. A. SHIELDS, AND C. E. HORTH \\ From the Department of Medicine, Hope Hospital (University of Manchester School of Medicine), Salford, \\ the Department of Medical Physics, The Royal Infirmary, Manchester, and the Biochemical Pharmacology \\ Department, G. D. Searle Company Limited, High Wycombe
}

SUMMARY Fourteen apparently healthy patients with ileostomies were found to be depleted of total exchangeable sodium and potassium, but had normal serum electrolyte concentrations and normal extracellular fluid and total body water volumes. The low exchangeable sodium and potassiums were thus primarily due to depletion of the intracellular compartment. There was no evidence of renal or intestinal conservation of these ions and plasma aldosterone, renin activity, and prolactin concentrations were normal in most and only moderately raised in a few. This apparent lack of any hormonal compensatory change to the electrolyte depletion may be due to the normality of the extracellular fluid volume and electrolyte concentrations. These patients seem to have adapted to a stable but depleted intracellular sodium and potassium state.

Patients left with an ileostomy after total colectomy are liable to develop sodium depletion states (Gallagher et al., 1962), and it has been demonstrated that some patients, even when they are apparently in good health, have persistent salt and water depletion (Clarke et al., 1967: Hill et al., 1975). There is evidence to suggest that ileal mucosal function changes after colectomy and 'adapts' to the new situation by enhancing its capacity to absorb sodium. Isaacs et al. (1976) have demonstrated, for instance, that patients with ileostomies have an increased potential difference across their ileal mucosa, and it is possible that this reflects enhanced absorption of sodium by the mucosa. Similarly, it is recognised that, after an ileostomy has been formed, the volume of ejecta decreases in the weeks after surgery, suggesting that the ileostomy adapts in some way (LeVeen et al., 1962; Wright et al., 1969).

The mechanism for this supposed change of functioning is unknown. One possibility is that the function of the small intestine may alter in response to circulating levels of salt-retaining hormones. It is known that sodium absorption in the human colon is aldosterone sensitive (Edmonds

${ }^{1}$ Address for reprints: Professor L. A. Turnberg, Department of Medicine, Hope Hospital, Eccles Old Road, Salford M6 8HD. and Godfrey, 1970). and there is some evidence that angiotensin may also influence the absorptive capacity of the colon (Davies et al., 1972). Prolactin has also been implicated in the control of intestinal ion transport (Mainoya, 1975). Evidence that the human small intestine shares this ability to respond to such hormones is, however, imperfect and conflicting.

Isaacs et al. (1976) demonstrated in an earlier study that plasma aldosterone concentrations were low or normal in patients with ileostomies, despite the observation that in these same patients electrical potential differences were raised across their ileal mucosa, and despite the observation of others (Clarke et al., 1967; Hill et al., 1975) that similar patients are usually in a state of mild continuing salt and water depletion.

We have therefore investigated a group of established ileostomy patients to assess the degree of electrolyte and water depletion and to search for evidence of adaptive renal or hormonal responses.

\section{Method}

\section{PATIENTS}

Fourteen apparently healthy patients with ileostomies gave their consent to the study, the protocol having been approved by the Salford Area Health Authority (Teaching) Ethical Committee. 
There were nine women of mean age 50 years (range 34 to 70 years) and five men, mean age $51 \cdot 2$ years (range 35 to 68 years). The ileostomies of all the subjects had been formed at least six months before the study, and the mean time since its formation in the women was 6.4 years (range 1.5 to 14 years) and in the men 6.9 years (range 0.5 to 19 years). The clinical details of these subjects including their diagnoses and mean blood pressure (arithmetical mean of lying and standing values) are shown in Table 1.

Table 1 Clinical details of patients

\begin{tabular}{|c|c|c|c|c|c|c|}
\hline No. & Sex & $\begin{array}{l}\text { Age } \\
(y r)\end{array}$ & $\begin{array}{l}\text { Weight } \\
(\mathrm{kg})\end{array}$ & Diagnosis* & $\begin{array}{l}\text { Duration } \\
\text { (yr) }\end{array}$ & $\begin{array}{l}\text { Blood pressure } \\
\text { (mm } \mathrm{Hg})\end{array}$ \\
\hline 1 & $\mathbf{F}$ & 54 & 51.9 & UC & 1.5 & $125 / 85$ \\
\hline 2 & $F$ & 35 & 52 & C & 3 & $140 / 80$ \\
\hline 3 & $\mathbf{F}$ & 34 & 50.3 & UC & 14 & $150 / 100$ \\
\hline 4 & $\mathbf{F}$ & 58 & 55 & UC & 6 & $180 / 110$ \\
\hline 5 & $\mathbf{F}$ & 40 & 58.2 & C & 2 & $124 / 80$ \\
\hline 6 & $\mathbf{F}$ & 57 & $57 \cdot 3$ & UC & 8 & $180 / 120$ \\
\hline 7 & $\mathbf{F}$ & 43 & 49 & C & 6 & $185 / 110$ \\
\hline 8 & $\mathbf{F}$ & 49 & $51 \cdot 8$ & UC & 13 & $146 / 84$ \\
\hline 9 & $\mathbf{F}$ & 70 & $55 \cdot 1$ & UC & 4 & $155 / 95$ \\
\hline 10 & $\mathbf{M}$ & 68 & 58.5 & UC & 0.5 & \\
\hline 11 & $\mathbf{M}$ & 66 & $70 \cdot 4$ & UC & 19 & $150 / 90$ \\
\hline 12 & $\mathbf{M}$ & 45 & $81 \cdot 7$ & UC & 3 & $100 / 65$ \\
\hline 13 & $\mathbf{M}$ & 35 & $62 \cdot 2$ & $\mathrm{C}$ & 6 & $110 / 70$ \\
\hline 14 & $\mathbf{M}$ & 42 & 76.5 & UC & 6 & $170 / 118$ \\
\hline
\end{tabular}

*UC: Ulcerative colitis. C: Crohn's disease.

\section{PROCEDURES}

Each subject attended at midday on the first day, when a history was taken, examination performed, and measurements of their height, weight, and lying and standing blood pressure were recorded. While still ambulant, a venous blood sample was taken for estimation of plasma sodium, potas- sium, aldosterone, renin activity, and prolactin.

After they had been instructed on the collection of 24 hour urine and ileostomy samples the subjects returned to their normal activities, to return with their completed collections the next day.

On the second day, measurement of their total exchangeable sodium (TENa) and potassium (TEK), extracellular fluid volume (ECFV) and total body water (TBW) was started using a modification of the method of Skrabal et al. (1970). An intravenous injection of a sterile solution containing $50 \mu \mathrm{Ci}{ }^{43} \mathrm{~K}, 30 \mu \mathrm{Ci}{ }^{77} \mathrm{Br}, 20 \mu \mathrm{Ci}{ }^{24} \mathrm{Na}$, and $0.4 \mathrm{mCi}$ THO was administered after taking a venous blood sample for background counting. The subjects returned at the same time on the third day with a second 24 hour ileostomy collection and a 23 hour pooled urine collection (Fig. 1). They then had a venous blood sample taken and a 'spot', 24th hour, urine sample was collected to provide equilibrium isotope levels. The subjects were not allowed fluids for four hours before the injection of the isotopes, or for four hours before the study was completed.

The samples, after separation by ion exchange resins, were counted under identical conditions using Ultragamma (Wallac) and Liquid Scintillation $\beta$ (Wallac) counters.

In order to compare the observed results with those expected for normal subjects of the same weights as our patients, calculated expected values were obtained using the formulae of Moore (1967).

Aldosterone was measured using a technique described by Isaacs et al. (1976) and prolactin by use of a CIS Kit (Eurotope Services). Plasma renin activity was measured using a modification of an angiotensin I trapping method of Poulsen and Jorgensen (1974).
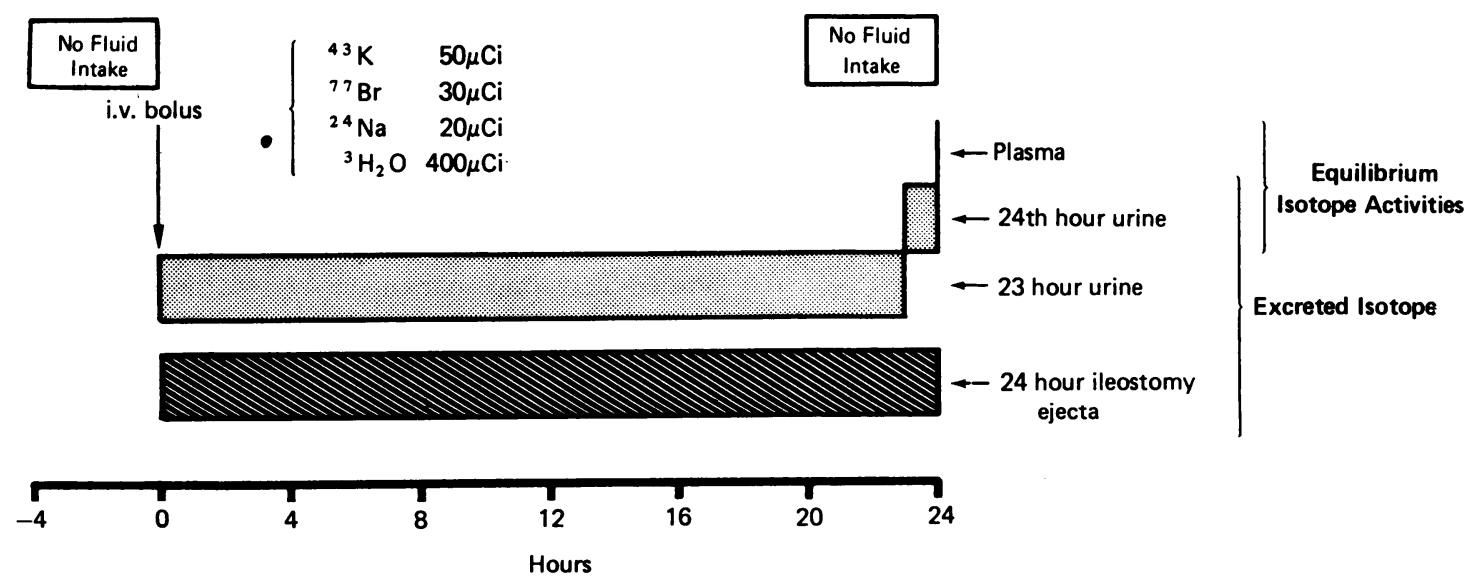

Fig. 1 Method for the simultaneous measurement of total exchangeable sodium and potassium, total body water, and extracellular fluid volume (bromide space). 
Electrolytes were measured using an Eel automated flame photometer.

\section{Results}

TOTAL EXCHANGEABLE SODIUM (TENa) AND POTASSIUM (TEK)

Using the isotope dilution principle, measurements of TENa were completed in 13 subjects and of TEK in 12 subjects.

The results of these measurements, together with their paired expected values, for normal subjects of the same weight are shown in Fig. 2.

All the women and one of the men had lower TENa levels than expected. The mean value for the whole group for observed TENa (37.4 \pm 4.2 mmol. $\mathrm{kg}^{-1}$ mean $\left.\pm \mathrm{SD}\right)$ was significantly lower than the calculated expected value $(40.8 \pm 1.9$ mmol. $\mathrm{kg}^{-1}$ ) $\mathrm{P}<0.01$ (paired $t$ test). When the sexes were separated, the females alone also showed a significant reduction $(\mathrm{P}<0.001)$.

Of the 12 subjects whose TEK measurements were completed, all but one male had lower TEK levels than the expected normal values. The observed level of TEK of $33 \pm 9.3 \mathrm{mmol}$. $\mathrm{kg}^{-1}$ was significantly lower, $P<0.005$, than the calculated expected value of $41.9 \pm 4 \cdot 1 \mathrm{mmol}$. $\mathrm{kg}^{-1}$. When separated into males and females, it was only in the latter group that the reduction reached statistical significance $(P<0.001)$. The observed values in the male subjects just failed to reach significance, probably reflecting the small number of subjects in this group.

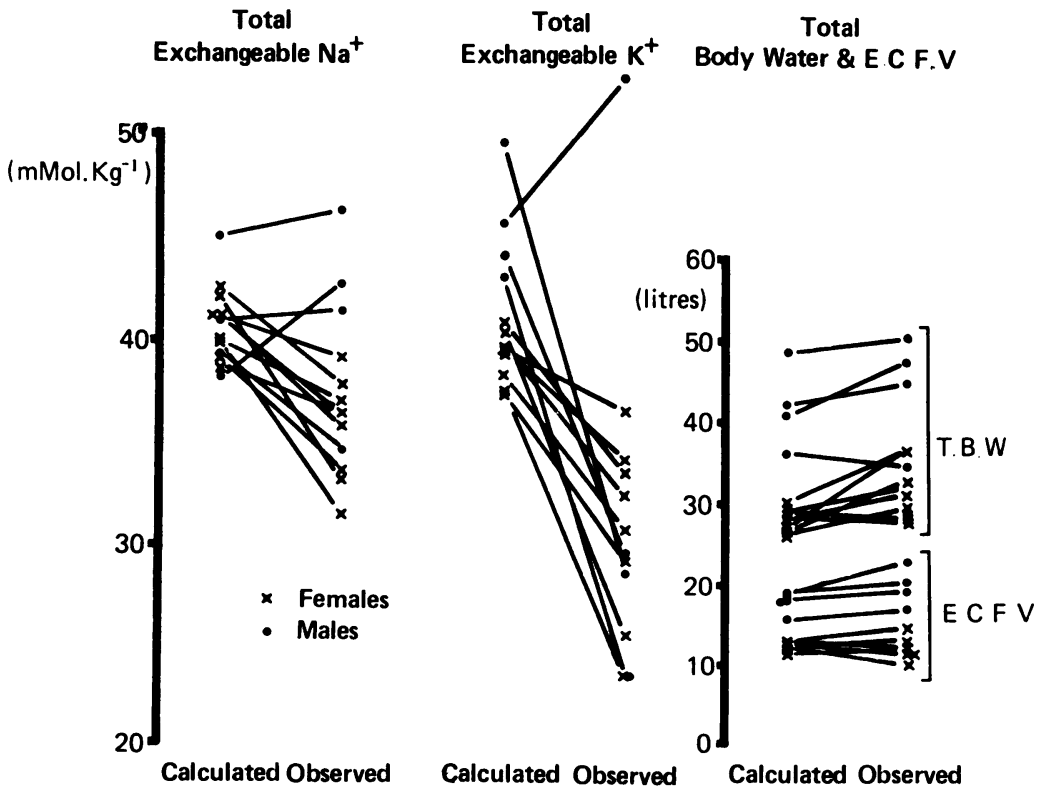

TOTAL BODY WATER AND EXTRACELLULAR FLUID VOLUME

While the measurements of TENa and TEK were being made, the patients' total body water and extracellular fluid volume were estimated. There was no significant difference between the observed and calculated values of total body water in either the male or female subjects. Similarly, the observed values for extracellular fluid volume, as measured by the bromide space, were not significantly different from the expected normal values.

\section{INTRACELLULAR EXCHANGEABLE SODIUM AND POTASSIUM}

The depletion of TENa and TEK was not due to a reduction in the extracellular levels of these ions, as these subjects had normal values for total body water and extracellular fluid volume (Fig. 2), as well as normal plasma sodium and potassium concentrations (Table 2).

The depletion, therefore, must have been due to a reduction in exchangeable intracellular sodium and potassium. These values were calculated using the formula: Exchangeable intracellular ion ( $\mathrm{mmol})=$ total exchangeable ion (mmol) - plasma ion concentration (mmol. $\left.1^{-1}\right) \times$ extracellular fluid volume (litres) ).

Similar values for normal subjects of the same weight were calculated and are shown in Fig. 3. Significant depletion of exchangeable intracellular sodium was found in both men and women, whereas significant exchangeable intracellular potassium depletion was found only in the women, the lowered

Fig. 2 Calculated and observed total exchangeable sodium and potassium, total body water, and extracellular fluid volume in ileostomy patients. 
Table 2 Plasma sodium and potassium concentrations and 24 hour urinary and ileostomy outputs

\begin{tabular}{|c|c|c|c|c|c|c|}
\hline & \multicolumn{2}{|l|}{ Sodium } & \multicolumn{2}{|c|}{ Potassium } & \multicolumn{2}{|c|}{ Volume } \\
\hline & Male & Female & Male & Female & Male & Female \\
\hline $\begin{array}{l}\text { Plasma concentration } \\
\text { (mmol.1-1) } \\
24 \text { hour urine output } \\
\left.\text { (mmol. } 24 \mathrm{~h}^{-1} \text { and } 1.24 \mathrm{~h}^{-1}\right) \\
24 \text { hour ileostomy output } \\
\left(\mathrm{mmol} 24 \mathrm{~h}^{-1} \text { and } 1.24 \mathrm{~h}^{-1}\right)\end{array}$ & $\begin{array}{l}136 \cdot 4 \\
\pm 3 \cdot 2 \\
87 \cdot 9 \\
\pm 52 \cdot 4 \\
59 \\
\pm 34 \cdot 2\end{array}$ & $\begin{array}{c}136 \cdot 4 \\
\pm 2 \cdot 9 \\
52 \cdot 8 \\
\pm 33 \cdot 9 \\
64 \cdot 3 \\
\pm 41 \cdot 1\end{array}$ & $\begin{array}{r}4 \cdot 0 \\
\pm \quad 0 \cdot 2 \\
69 \\
+18 \cdot 6 \\
4 \cdot 7 \\
+2 \cdot 4\end{array}$ & $\begin{array}{r}3.9 \\
+0.4 \\
53.8 \\
\pm 16.4 \\
7 \cdot 5 \\
+\quad 9 \cdot 3\end{array}$ & $\begin{array}{c}1.31 \\
0.7 \\
0.62 \\
\pm 0.25\end{array}$ & $\begin{array}{r}0.99 \\
0.57 \\
0.59 \\
\pm 0.37\end{array}$ \\
\hline
\end{tabular}

All results expressed as mean $\pm \mathbf{S D}$.

male values failing to reach significance.

Thus, these subjects were depleted of sodium and potassium and measurements of urinary and ileostomy losses were undertaken to see if they were conserving these ions.

Urine and ileostomy sodium and potassium outputs The 24 hour urinary losses of sodium and potassium, together with the urine volume, are shown in Table 2. The females were losing a mean of $53 \mathrm{mmol}$ sodium and $54 \mathrm{mmol}$ potassium in 24 hours, with a mean urinary volume of 0.99 . The mean 24 hour outputs for the male subjects were $88 \mathrm{mmol}$ sodium and 69 mmol potassium with a mean urinary volume of 1.31. Ileostomy outputs were similar in volume and sodium output for both men and women (Table 2), while potassium output was greater in the women, but not significantly so.

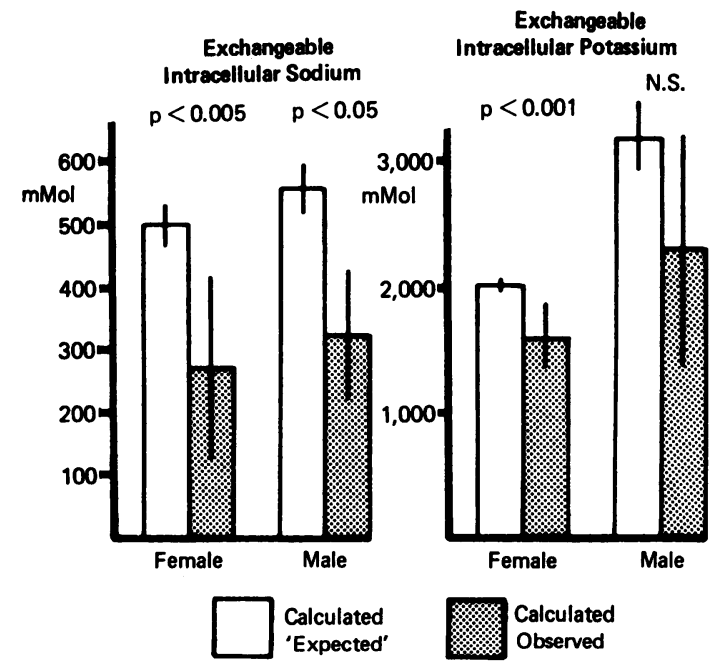

Fig. 3 Calculated 'expected' and observed exchangeable intracellular sodium and potassium in ileostomy patients.

Thus, despite the intracellular electrolyte depletion, there was no obvious renal or ileostomy conservation of sodium or potassium.
Plasma aldosterone, renin activity, and prolactin

The individual values for each of these hormones in eight women and five men are shown in Fig. 4, together with the normal ranges.

In only one normotensive female was there a raised concentration of plasma aldosterone, and she also had the second highest activity of plasma renin, and the lowest output of urinary sodium. Three other females had mildly raised activities of plasma renin, and three of the men had slightly raised concentrations of prolactin.

Plasma aldosterone concentrations correlated with plasma renin activity $(P<0.005$ Kendall's rank correlation two sided) for the 13 subjects, but none of the hormone concentrations significantly correlated with urine or ileostomy electrolyte losses, or with exchangeable ion levels.

\section{Discussion}

The patients on whom this study was performed were all fit, most were at work, and none had any gastrointestinal symptoms. No patient was receiving steroids and none was taking salt or potassium supplements. From their ileostomy and urine outputs they were similar to those patients studied by Gallagher et al. (1962), Clarke et al. (1967), and Isaacs et al. (1976).

Critchley et al. (1977) from this department have validated our use of the technique of Skrabal et al. (1970) for measuring TENa, TEK, extracellular fluid volume, and total body water, showing no significant difference between the observed values in control subjects and the calculated values for normal subjects of the same weight using Moore's formulae.

In addition, we have obtained similar results using different formulae for calculating the expected normal values (Muldowney et al., 1957).

Our results show that these established, apparently healthy ileostomy patientsare sodium depleted, a finding previously reported by Clarke et al. (1967) and Hill et al. (1975). The potassium depletion that we have also demonstrated has, however, not 


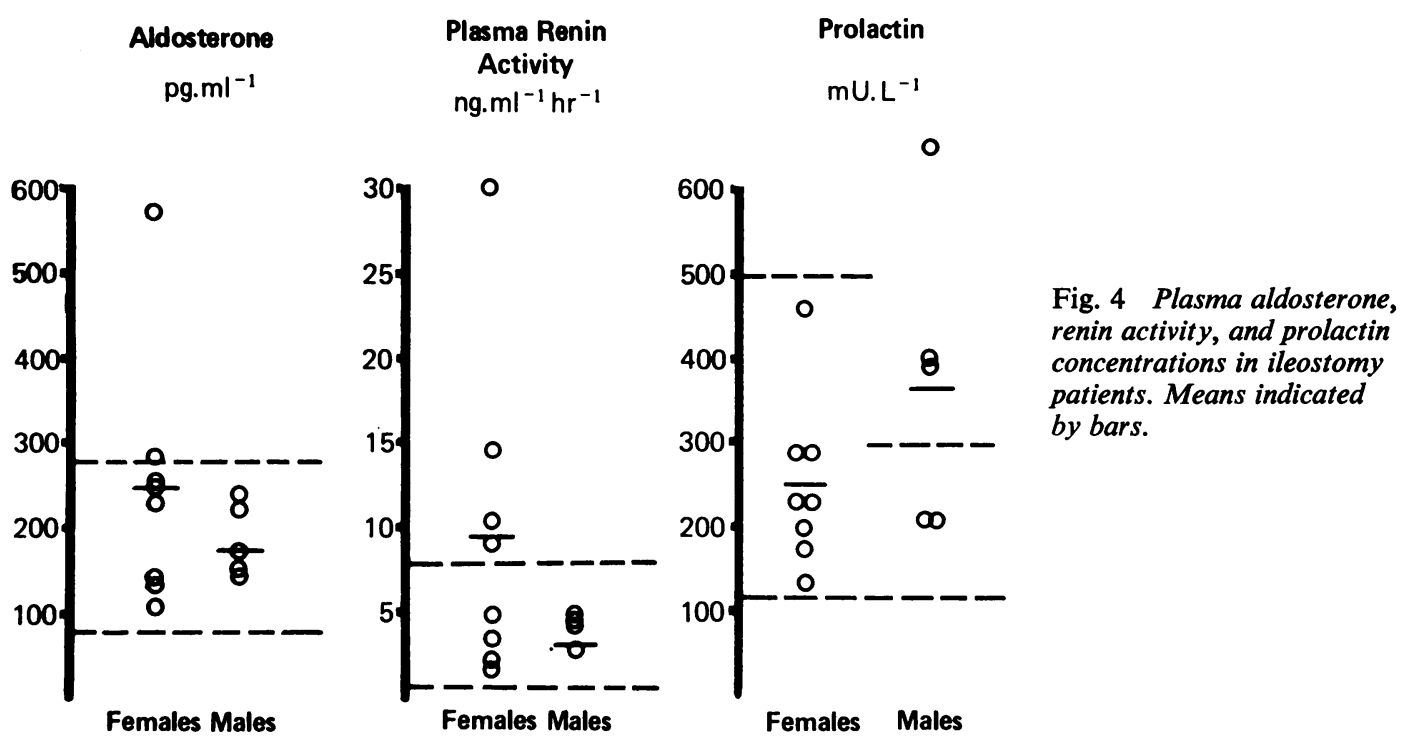

previously been reported. Clarke et al. (1967) and Hill et al. (1975) demonstrated water depletion in their subjects but we have been unable to confirm this. These workers did not measure the size of the extracellular fluid volume, which we also found to be normal. None of our patients had postural hypotension or other clinical signs of dehydration, a not unexpected finding in view of their normal extracellular fluid volume. Only one subject had a low mean blood pressure and five had hypertension, none of whom was on treatment. These readings were taken only once and may thus be an overestimate due to stress. The normal plasma concentrations of sodium and potassium, and the normal extracellular fluid volume, in the face of depletion of total exchangeable levels of these ions, must mean that the depletion was predominantly intracellular. Furthermore, it is the exchangeable sodium and potassium, in such cells as those of muscle and fat, rather than those more slowly exchanging cells in bone, which are likely to have been depleted.

It might have been expected that normal renal and hormonal adaptive responses to depletion would have occurred. Our subjects, however, lost a significant amount of sodium and potassium in their urine, probably reflecting intake. In addition, salt-retaining hormone concentrations were mostly within the normal range and the rises were slight in the few subjects who had raised concentrations. As renal blood flow and plasma sodium concentrations are the main controlling factors involved in the renin, angiotensin, aldosterone pathway,

it is perhaps not surprising that our subjects, with their normal extracellular fluid compartment, did not demonstrate renal or hormonal adaptive responses, despite their total body depletion.

In addition, there is some evidence (Bartter, 1956) that potassium depletion lowers aldosterone production, and Johnson et al. (1957) have suggested that potassium depletion may reduce the aldosterone response to sodium deprivation.

Thus, our patients have a paradoxically normal salt-retaining steroid activity in the face of $\mathrm{Na}$ and $\mathrm{K}$ depletion. It appears that, under these conditions, the extracellular electrolyte milieu may be maintained at the expense of intracellular depletion. Certainly this intracellular depletion of both ions seems to be tolerated remarkably well by these clinically fit patients.

The mechanism by which this redistribution occurs is unclear. Longitudinal studies in patients before and after colectomy might help our understanding of the underlying mechanisms but, unfortunately, many patients are receiving steroids and/or intravenous fluids at the time of operation, both of which might influence results.

We wish to thank the Ileostomy Association of Great Britain for their co-operation, and Miss K. Pimblett and Mrs. L. Hall for their technical help. This work was generously supported by a grant from G. D. Searle Company Limited.

\section{References}

Bartter, F. C. (1956). The role of aldosterone in normal 
homeostasis and in certain disease states. Metabolism, 5, 369-383.

Clarke, A. M., Chirnside, A., Hill, G. L., Pope, G., and Stewart, M. K. (1967). Chronic dehydration and sodium depletion in patients with established ileostomies. Lancet, 2, 740-743.

Critchley, M., Herman, K. J., Harrison, M., Shields, R. A., and Liversedge, L. A. (1977). Value of exchangeable electrolyte measurement in the treatment of myasthenia gravis. Journal of Neurology, Neurosurgery and Psychiatry, 40, 250-252.

Davies, N. T., Munday, K. A., and Parsons, B. J. (1972). Studies on the mechanism of action of angiotensin on fluid transport by the mucosa of rat distal colon. Journal Endocrinology, 54, 483-492.

Edmonds, C. J., and Godfrey, R. C. (1970). Measurement of electrical potentials of the human rectum and pelvic colon in normal and aldosterone-treated patients. Gut, 11, 330-337.

Gallagher, N. D., Harrison, D. D., and Skyring, A. P. (1962). Fluid and electrolyte disturbances in patients with long-established ileostomies. Gut, 219-223.

Hill, G. L., Goligher, J. C., Smith, A. H., and Mair, W. S. J. (1975). Long term changes in total body water, total exchangeable sodium and total body potassium before and after ileostomy. British Journal of Surgery, 62, 524-527.

Isaacs, P. E. T., Horth, C. E., and Turnberg, L. A. (1976). The electrical potential difference across human ileostomy mucosa. Gastroenterology, 70, 52-58.

Johnson, B. B., Lieberman, A. H., and Mulrow, P. J.
(1957). Aldosterone excretion in normal subjects depleted of sodium and potassium. Journal of Clinical Investigation, 36, 757-766.

LeVeen, H. H., Lyons, A., and Becker, E. (1962). Physiologic adaptation to ileostomy. American Journal of Surgery, 103, 35-41.

Mainoya, J. R. (1975). Further studies on the action of prolactin on fluid and ion absorption by the rat jejunum. Endocrinology, 96, 1158-1164.

Moore, F. D. (1967). Body composition and its measurement in vivo. British Journal of Surgery, 54, 431-435.

Muldowney, F. P., Crooks, J., and Bluhm, M. M. (1957). The relationship of total exchangeable potassium and chloride to lean body mass, red cell mass and creatinine excretion in man. Journal of Clinical Investigation, 36, 1375-1381.

Poulsen, K., and Jorgensen, J. (1974). An easy radioimmunological microassay of renin activity, concentration and substrate in human and animal plasma and tissues based on Angiotensin-I trapping by antibody. Journal of Clinical Endocrinology and Metabolism, 39, 816-825.

Skrabal, F., Arnot, R. N., Helus, F., Glass, H. I., and Joplin, G. F. (1970). A method for simultaneous electrolyte investigations in man using ${ }^{77} \mathrm{Br},{ }^{48} \mathrm{~K}$ and ${ }^{24} \mathrm{Na}$. International Journal of Applied Radiation and Isotopes, 21, 183-191.

Wright, H. K., Cleveland, J. C., Tilson, M. D., and Herskovic, T. (1969). Morphology and absorptive capacity of the ileum after ileostomy in man. American Journal of Surgery, 117, 242-245. 